\title{
Polystyrene grafted onto high-cis-1,4 polybutadiene backbone via 'living' radical polymerization with 2,2,6,6-tetramethylpiperidinyl-1-oxy (TEMPO) radical
}

\author{
Z. S. $Y u^{1,2^{*}}, Y . L i^{1}, Y . R$. Wang $^{1}$ \\ ${ }^{1}$ Department of Polymer Science and Engineering, Faculty of Chemical, Environmental and Biological Science and \\ Technology, Dalian University of Technology, Dalian 116012, People's Republic of China \\ ${ }^{2}$ Shanghai Research Institute of Petrochemical Technology, SINOPEC, Shanghai 201208, People's Republic of China
}

\begin{abstract}
A stable nitroxide radical (2,2,6,6-tetramethylpiperidinyl-1-oxy, TEMPO) was employed to a grafting polymerization of styrene onto the high-cis-1,4 polybutadiene (PB) rubber initiated by 1,1-bis(tert-butylperoxy)cyclohexane (DP275B). The influence of TEMPO/DP275B ratio on the reaction progress, molecular structure, mechanical performance and fracture behavior of the toughened polystyrenes (PS) was systematically characterized. The results showed that a moderate amount of TEMPO used is favorable to the morphology and properties of the as-prepared products, which fracture with a semi-ductile mode. While increasing TEMPO dosage, both rubber grafting and particle size distribution become weaker, and as a result the material also tends to be very brittle and unstable under impact.
\end{abstract}

Keywords: polymer composites, living radical polymerization, TEMPO, mechanical properties, fracture mechanism

\section{Introduction}

Graft polymers became highly attractive materials and drew more and more attention due to their potential applications as e.g. compatibilisers, thickening agents, tougheners and modifiers, etc. [1-5]. Graft copolymerization of vinyl monomers onto plastics is a very useful way to modify some special performances of the existing materials and expand their application range [6-10].

Compared with living ionic polymerization for graft polymers [11, 12], the advantages of living radical polymerization, e.g. nitroxide-mediated polymerization (NMP), are that the polymerization conditions required are less stringent, and the terminal group of initial graft segments (nitroxide group) is stable in air at room temperature and the intermediates can be isolated, stored and used as needed [9, 13]. Besides, the NMP method can combine the ease of polymerization with the fact that several monomers are capable of reaction [14]. Polymers with controlled molecular weight and narrow polydispersity can be synthesized by this controlled/stable free radical methodology $[15,16]$.

Several reports about the NMP method have recently appeared on the subject of the modification of polydienes or polymeric substrates through grafting copolymerization of vinyl monomers [17-24]. Commonly, the nitroxide moieties are firstly hung on the backbone of those substrates, which are endowed with functionalized group, and then in the presence of monomer, the grafts are grown from the nitroxide sites under thermal conditions. Howell et al. [25] reported a synthesis of PB (polybutadiene) with hanging nitroxide moieties to produce highimpact polystyrene (HIPS), and the grafting process was studied only by the comparison of the gel per-

\footnotetext{
${ }^{*}$ Corresponding author, e-mail: yvzx.sshy@sinopec.com
} (c) BME-PT 
meation chromatography (GPC) of the grafted polymer with the functionalized polymer. In the fundamental studies of the controlled grafting of PS on PB by Bonilla-Cruz et al. [26], not only the functionalization mechanisms were proposed, but the structure and level of grafting control were investigated. Nevertheless, some aspects regarding the microstructural morphology and the mechanical performances of the final products have not been reported in literature.

In the present study, nitroxide-mediated polymerization has been conducted for synthesizing PB- $g$ PS copolymers in the presence of difunctional radical initiator (DP275B) and stable nitroxide radical (TEMPO), and the grafting polymerization behavior of the resulting product is characterized by size exclusion chromatography (SEC). Experiments are also designed to investigate the effect of nitroxide/ initiator (TEMPO/DP275B) ratio on the polymerization kinetics behavior, phase inversion progress, and the structural and mechanical properties of asproduced resins. The corresponding toughening mechanisms are evaluated by means of scanning electron microscopy.

\section{Experimental}

\subsection{Materials}

High-cis-1,4-PB rubber (Trade name: BR9004) was supplied by Yanshan Petrochemical Co. (Beijing, China), and its molecular parameters are illustrated in Table 1. Styrene and ethylbenzene were obtained from Daqing Petrochemical Co. (Daqing, China). St was vacuum distilled over $\mathrm{CaH}_{2}$ (Jinke Chemicals Co., Tianjin, China) just before polymerization. DP275B (80.7 wt $\%$ in ethylbenzene) was obtained from Qiangsheng Chemical Co. (Changshu, China) and used as received. TEMPO purchased from $\mathrm{J} \&$ K Chemical Ltd. (Utah, USA), and solvents from Hongyan Chemical Co. (Tianjin, China) such as acetone, butanone, chloroform, methanol and tetrahydrofuran were used as received.

\subsection{NMP preparation of PB- $g$-PS/PS composites}

The NMP polymerization was carried out under nitrogen in a dried stainless steel reactor (11) equipped with an anchor-type magnetic stirring bar (Xiandali Petrochemical Ltd., Beijing, China). The typical polymerization process is as follows: firstly, BR9004 (30.0 g) added into the reactor was dissolved in styrene $(370.0 \mathrm{~g}, 410.5 \mathrm{ml})$ under nitrogen by stirring at ambient temperature overnight to obtain a $7.5 \mathrm{wt} \%$ of rubber/monomer solution. After complete dissolution, DP275B (0.458 g, $1.42 \mathrm{mmol})$ and TEMPO ( $0 \sim 0.261 \mathrm{~g}, 0 \sim 1.66 \mathrm{mmol}$, Table 2$)$ successively dissolved in ethylbenzene $(30.0 \mathrm{~g}$, $34.6 \mathrm{ml}$ ) were simultaneously charged into the reactor and dispersed in the previous rubber solution under the agitation. Then the system was heated by circulating heated oil to $105^{\circ} \mathrm{C}$ for pre-polymerization. The pre-polymerization continued at a pressure of $0.2 \mathrm{MPa}$ while being stirred at a rate of $375 \mathrm{rpmn}$ for $5 \mathrm{~h}$. The partially polymerized system was transferred to a quick-opening plate reactor (Xiandali Petrochemical Ltd., Beijing, China) and further performed a post-polymerization at $150^{\circ} \mathrm{C}$ for $4 \mathrm{~h}$. Finally, the produced polymer composite was dissolved in chloroform $(1.41 \mathrm{~kg}, 0.95 \mathrm{l})$ and precipitated into methanol $(1.19 \mathrm{~kg}, 1.5 \mathrm{l})$, and the obtained polymer was cut into granules and dried at $50^{\circ} \mathrm{C}$ in a vacuum oven under $10^{-1} \mathrm{~Pa}$ for $48 \mathrm{~h}$ to strip off the residual monomer and solvent.

Table 1. Molecular parameters of high-cis-1,4-PB substrate

\begin{tabular}{|c|c|c|c|c|c|c|}
\hline \multirow{2}{*}{ Substrate } & \multicolumn{3}{|c|}{ Microstructures [\%] } & \multirow{2}{*}{$M_{n} \cdot 10^{-4}$} & \multirow{2}{*}{ Polydispersity } & \multirow{2}{*}{$\begin{array}{c}\text { Viscocity in styrene (5\%) } \\
{[\mathrm{mPa} \cdot \mathrm{s}]}\end{array}$} \\
\hline & vinyl-1,2 & cis-1,4 & trans $-1,4$ & & & \\
\hline BR9004 & 1.5 & 97.0 & 1.5 & 8.1 & 3.81 & 153.8 \\
\hline
\end{tabular}

Table 2. Reaction conditions for NMP of styrene onto PB, where $R=$ TEMPO/DP275B

\begin{tabular}{|c|c|c|c|c|c|c|}
\hline \multirow{2}{*}{ Run } & \multirow{2}{*}{$\begin{array}{l}\text { TEMPO } \\
\text { [mmol] }\end{array}$} & \multirow{2}{*}{$\begin{array}{l}\text { DP275B } \\
\text { [mmol] }\end{array}$} & \multirow{2}{*}{$\mathbf{R}$} & \multirow{2}{*}{$\begin{array}{c}\mathbf{k}_{\mathrm{P}}{ }^{\prime \prime} \cdot 1000 \\
{\left[\mathrm{~min}^{-1}\right]}\end{array}$} & \multicolumn{2}{|c|}{ Phase inversion point } \\
\hline & & & & & $\mathbf{x}[\%]$ & $\eta[\mathrm{Pa} \cdot \mathrm{s}]$ \\
\hline 1 & 0.00 & 1.42 & 0.00 & 5.58 & 14.7 & 3.71 \\
\hline 2 & 0.47 & 1.42 & 0.33 & 3.31 & 19.2 & 3.34 \\
\hline 3 & 0.95 & 1.42 & 0.67 & 2.66 & 23.6 & 2.02 \\
\hline 4 & 1.66 & 1.42 & 1.17 & 1.51 & 30.5 & 1.90 \\
\hline
\end{tabular}

$k_{\mathrm{P}}{ }^{\prime \prime}, x$ and $\eta$ are the abbreviation of apparent propagation rate constant, monomer conversion and system viscosity, respectively. 


\subsection{Separation of free PS from PB-g-PS}

$1.0 \mathrm{~g}$ of as-produced polymer composite was dissolved in $30.0 \mathrm{ml}$ of mixed solvent (acetone/ butanone $=50: 50, \mathrm{v} / \mathrm{v}$ ). Then, $15.0 \mathrm{ml}$ of methanol was added into this solution for separating the two fractions. The PB-g-PS fraction was recovered as the precipitate at the bottom and the free PS $\left(\mathrm{PS}_{\mathrm{f}}\right)$ fraction was recovered from the remaining emulsion formed. Both polymers were dried under vacuum and used for characterizations.

\subsection{Characterization techniques}

\subsubsection{Characterizations of conversion, viscosity and grafting}

Monomer conversion was detected by a 2WA-J Abbe refractometer (Shanghai Yice Apparatus \& Equipment Co., China). The apparent viscosity was determined by a NDJ-1 rotary viscometer (Shanghai Precision \& Scientific Instrument Co., China). The PS-grafted rubber phase was characterized for its grafting parameters, i.e. grafting degree (GD) and rubber phase volume fraction (RPVF), which could be calculated with Equations (1) and (2):

$\mathrm{GD}[\%]=100 \cdot \frac{m(\mathrm{Gel})-m(\mathrm{~PB})}{m(\mathrm{~PB})}$

$\operatorname{RPVF}[\%]=100 \cdot \frac{m(\mathrm{Gel})}{m\left(\mathrm{PS}_{\mathrm{f}}\right)+m(\mathrm{Gel})}$

where $m(\mathrm{Gel}), m(\mathrm{~PB})$ and $m\left(\mathrm{PS}_{\mathrm{f}}\right)$ are the weights of the insoluble part, $\mathrm{PB}$ and $\mathrm{PS}_{\mathrm{f}}$ in sample, respectively.

\subsubsection{Size exclusion chromatography (SEC)}

The number average molecular weight $\left(M_{\mathrm{n}}\right)$ and polydispersity of $\mathrm{PS}_{\mathrm{f}}$ were determined by a Viscotek TDA302 SEC (Malvern Instruments, Malver, UK) with triple detection (refractive index, lowangle laser scatting and viscosity) in tetrahydrofu$\operatorname{ran}(1.0 \mathrm{ml} / \mathrm{min})$ at $40^{\circ} \mathrm{C}$. PS reference standards in the range of $4000 \sim 1.6 \cdot 10^{6}$ were used for the calibration of the system.

\subsubsection{Notched Izod impact testing}

The notched specimens were prepared by the Model 2 Injection Test Sample Molding Apparatus (UK) and conditioned at $23^{\circ} \mathrm{C}$ for at least $48 \mathrm{~h}$. The dimension of the specimens was $80 \times 10 \times 4 \mathrm{~mm}^{3}$. In middle part of their narrow face, a sharp notch tip of
$2 \mathrm{~mm}$ depth was cut with a 6951 reciprocating notchmilling machine (CEAST, ITW Test and Measurement Italia S.r.l, Pianezza, Italy). The tests were preformed on a CEAST RESILE Impactor (ITW Test and Measurement Italia S.r.l, Pianezza, Italy) at room temperature.

\subsubsection{Tensile testing}

All of the dumbbell-type specimens for the tensile tests were also injection-molded. The standard distance (effective part) was fixed in $20 \mathrm{~mm}$ and the cross section was $4.0 \times 2.1 \mathrm{~mm}^{2}$. The tensile tests were conducted on an INSTRON 5567 universal material testing machine (Norwood, MA, USA) at a constant speed of $5 \mathrm{~mm} / \mathrm{min}$ at $23^{\circ} \mathrm{C}$.

\subsubsection{Phase contrast microscope}

The prepolymer samples drawn from reactor at various polymerization times were dropped on one glass slide and covered by another. Then the compacted films were naturally dried in air for observation. An OLYMPUS Ahimadzu BH-2 phase contrast microscope (Olympus Corporation, Tokyo, Japan) was used to observe the phase separation state and the phase inversion progress under a magnification of 200 .

\subsubsection{Transmission electron microscope (TEM)} TEM images were obtained with a FEI TECNAI20 TEM (FEI, Hillsboro, Oregon, USA) at an accelerating voltage of $200 \mathrm{kV}$. The as-prepared samples were firstly ultramicrotomed with a diamond knife on a LEICA ULTRACUT Ultramicrotome (Leica, Wetzlar, Germany) at $-120^{\circ} \mathrm{C}$ to give ultrathin sections with a nominal thickness of $100 \mathrm{~nm}$. Then the sections were transferred to $\mathrm{Cu}$ grids of 200 mesh, and stained with $\mathrm{OsO}_{4}$ staining technique to enhance the contrast between rubber and matrix prior to the observation.

\subsubsection{Scanning electron microscope (SEM)}

Impact fracture surfaces of the specimens were coated with a thin gold layer on an EMITECH K550X Sputtering Coater (Quorum Technologies, East Grinstead, UK), and then observed to analyze the fracture nature and deformation mechanism. SEM analysis was performed by a FEI QUANTA200 SEM (FEI, Hillsboro, Oregon, USA) using a working voltage of $20 \mathrm{kV}$. 


\section{Results and discussion}

\subsection{Graft polymerization behavior}

The PB-g-PS/PS composites were synthesized via NMP method in the simultaneous presence of TEMPO and DP275B. The polymerization conditions utilized are summarized in Table 2. In the initial stage of polymerization, the thermal decomposition of DP275B (1) firstly occurs at $105^{\circ} \mathrm{C}$ and several free radicals are generated as the primary products, such as tert-butoxy radical (3), 1,1-cyclohexyl-dioxide radial (4) and so on, as shown in Figure 1. Taking radical (4) as an example, due to the low reactivity of the oxygen-centered free radical with TEMPO [20], once formed, it would undergo addition with styrene to give a carbon-centered free radical (5), which can be trapped by nitroxide radical. As a consequence, the intermediate (6) is pro- duced and temporarily in dormant state. Thus, an equilibrium between dormant spaces and nitroxide radicals is achieved and the polymerization rate can be controlled to some extent. In this case, with an enhancement of styrene conversion, the molecular weight of the $\mathrm{PS}_{\mathrm{f}}$ polymer (7) is gradually increased [21].

Meanwhile, Figure 2 shows that the functionalized macroalkoxyamine (here labeled as FPB) can also be synthesized by heating the BR9004 rubber in the simultaneous presence of TEMPO and tert-butoxy radical (3) at $105^{\circ} \mathrm{C}$. The radical (3) is formed directly from the initiator (1) and through the secondary decomposition of free radical (2) (Figure 1), and plays a significant role in the process of functionalization. Afterwards, a large amount of styrene monomers react with FPB to produce the PB-g-PS.

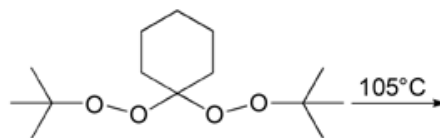

(1)

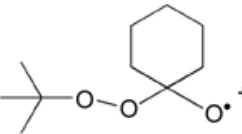

(2)<smiles>C[CH-]OC(C)(C)C</smiles>

(3)<smiles>CC(C)(C)OOC1([O])CCCCC1[18O][13C]1CCCC[13C]1([O])[18O]OC(C)(C)C</smiles>

a)

(2)

(4)

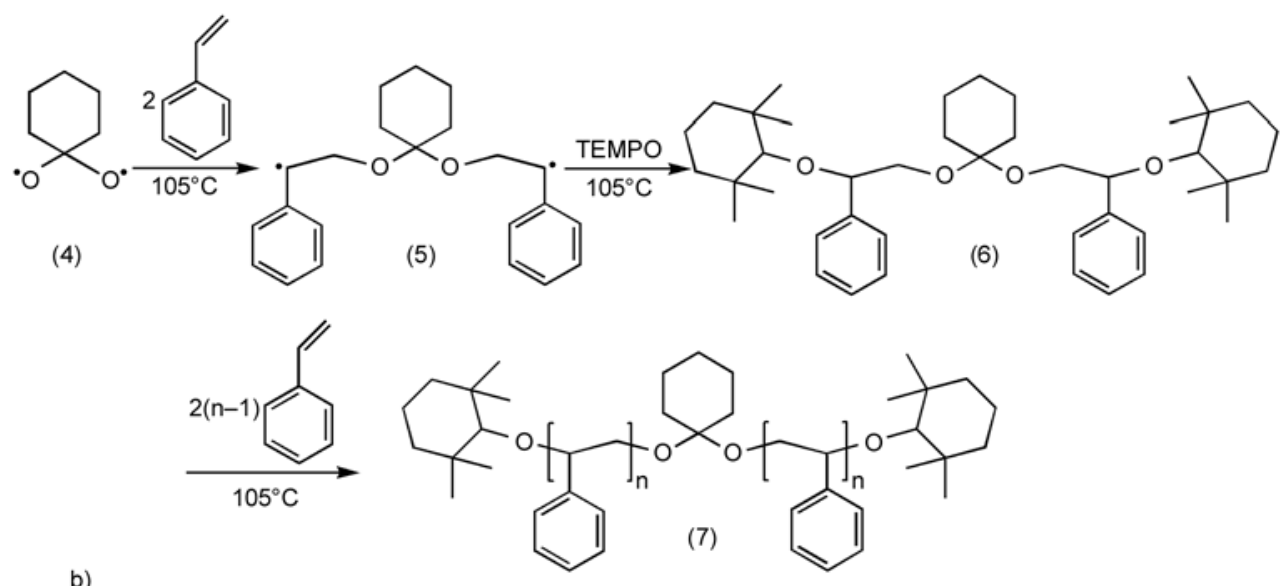

b)

Figure 1. a) Thermal decomposition scheme of DP275B and b) TEMPO-mediated polymerization of styrene initiated by one kind of free radical

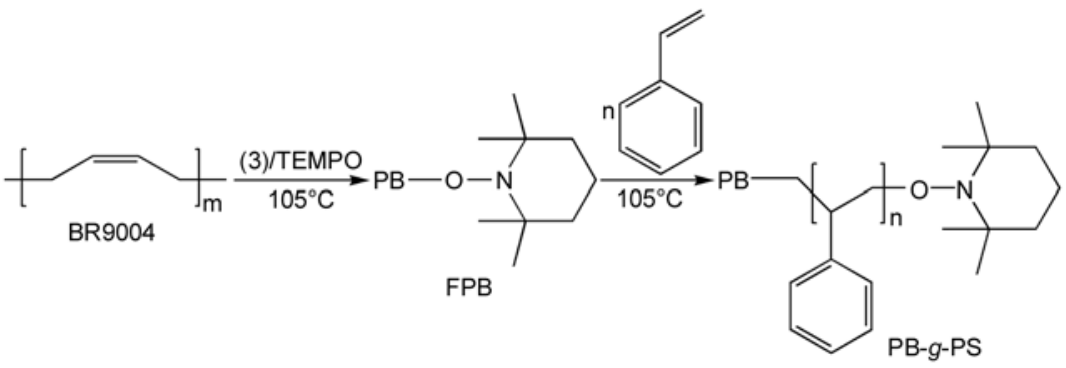

Figure 2. Reaction scheme of graft polymerization of styrene onto BR9004 rubber 
Both length and molecular weights of the grafted PS chains are controllably enhanced with increasing monomer conversion [21].

\subsection{Effect of $R$ values on the polymerization kinetics}

To acquire detailed information about the kinetic behavior of PB- $g$-PS/PS composite, the obtained monomer conversion $(x)$ from Abbe refractometer method underwent a logarithmic calculation $(-\ln (1-x / 100))$ and was plotted as the ordinate (Y-coordinate) (Figure 3a). And the slope of $-\ln (1-x / 100) \sim t$ curve was the apparent propagation rate constants $\left(k_{\mathrm{P}}{ }^{\prime \prime}\right)$ of monomer. The corresponding $k_{\mathrm{p}}$ " results are shown in Table 2. As seen, $-\ln (1-x / 100)$ exhibits approximately linear growth with the polymerization time under various $R$ values. Evidently, the reaction rate of styrene mediated by TEMPO decreases with increasing TEMPO/ DP275B ratio. This is mainly because that the carbon-centered free radicals generated in the prepolymerization process are successfully trapped by the TEMPO added, and to a certain extent, the prepolymerization rate can be efficiently controlled. Moreover, the inhibition effect of TEMPO radical on polymerization kinetics of styrene is obvious. As seen from Figure 3a, there exists an inhibition interval of about 60 minutes when adding inhibitor to the grafting polymerization system. This is also a clear evidence that inhibition typical for TEMPO occurred. Besides, the slightly changed inhibition interval under different TEMPO dosages may also account for a suitable amount of inhibitor in experimental range examined in favor of precise controllability of the grafting behavior.

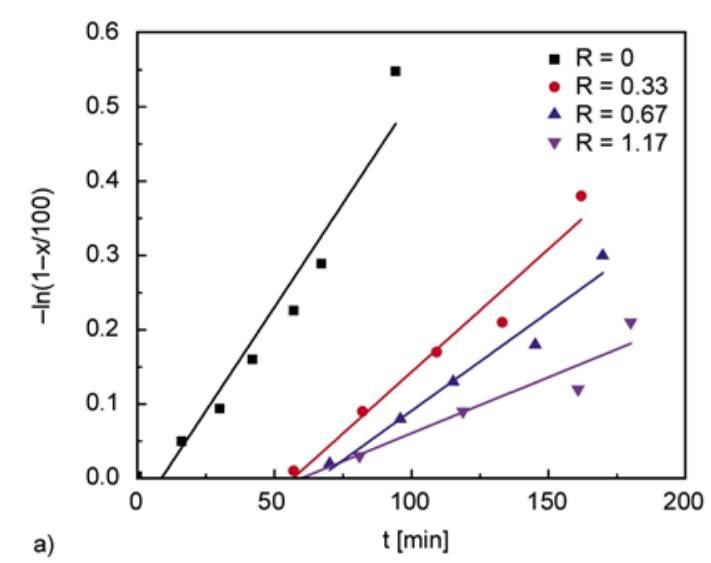

\subsection{Effect of $R$ values on phase inversion}

As known, rubber particles formed in phase inversion play an important role in resin-toughening. If phase inversion takes place incompletely, the products would present no excellent performance. So the study on phase inversion is of the utmost importance [27]. The relationship between the system viscosity $(\eta)$ and the monomer conversion $(x)$ under different $R$ values is plotted in Figure 3b. When no TEMPO is added, the polymerization rate is very fast, and simultaneously, the viscosity also increases swiftly. It can be decreased obviously with increasing the TEMPO dosage at the same conversionvalue of monomer. The phase inversion progress also tends to be remarkable, that is, the $\eta \sim x$ curve displays a significant elevating-descending-elevating change in phase inversion stage. Meanwhile, the conversion of styrene corresponding to the transition point is indeed improved (Table 2), which implies that a delayed phase inversion occurs.

A phase contrast microscope was applied for the optical observation of the phase inversion progress. At any $R$ value, it presents a similar process of phase behavior change. Figure 4 illustrates the relative phase contrast photomicrographs of the samples before, at and after the phase inversion point when $R$ value is 0.67 . The light-colored region represents the resin phase and the dark-colored region represents the rubber phase. The reaction mixture is firstly a continuous phase consisting in PB dissolved in styrene/ethylbenzene. After a certain degree of monomer conversion, a second phase consisting in PS dissolved in styrene/ethylbenzene is formed and dispersed as irregular drops in the continuous rubber phase (Figure 4a). That is, at a certain spinodal,

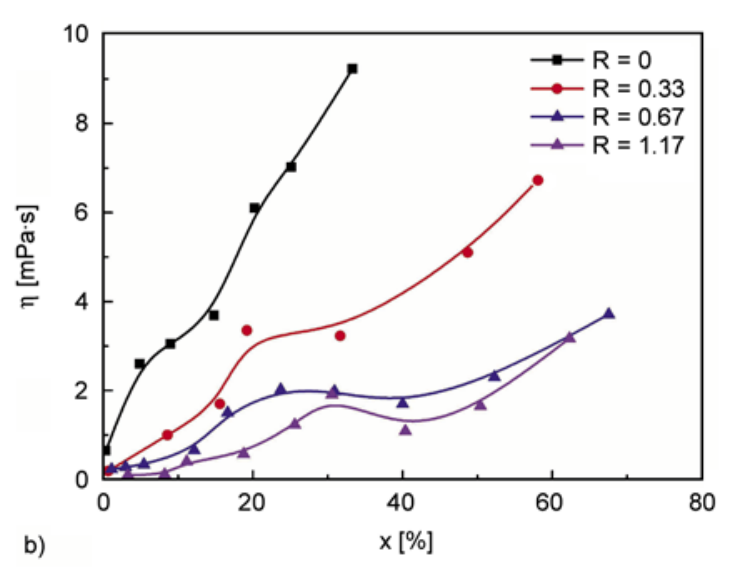

Figure 3. Effect of TEMPO/DP275B ratios on a) polymerization kinetics and b) phase inversion progress of styrene in BR9004 rubber system 
PS polymers start to nucleate, due to the incompatibility of newly produced PS with original rubber substrate. Besides, these droplets gradually grow while the polymerization degree of monomer

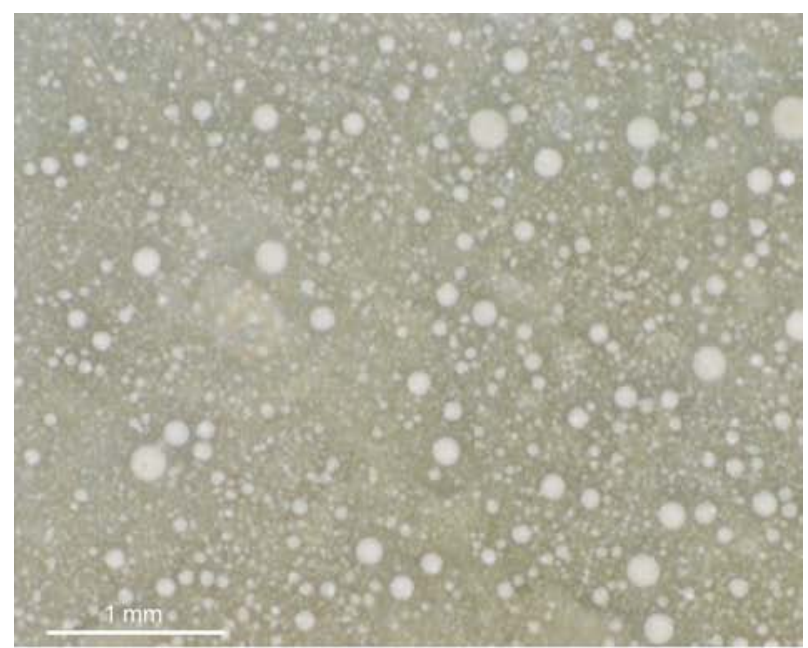

a)

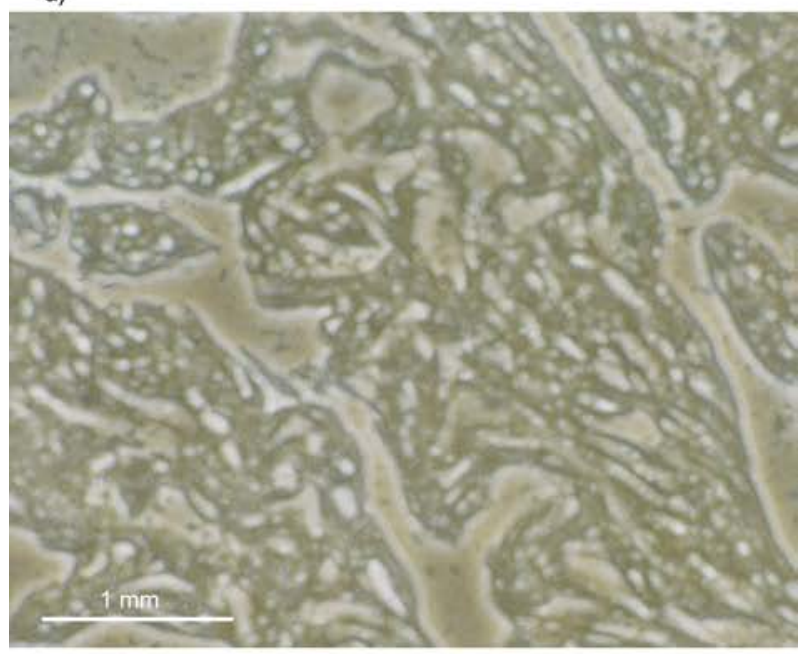

b)

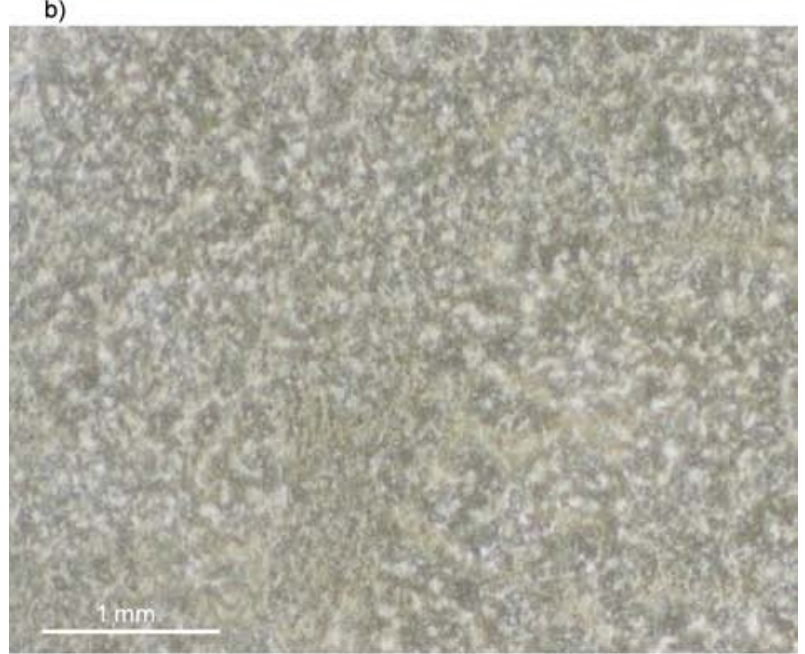

c)

Figure 4. Phase contrast microphotographs of composite $(R=0.67):$ a) $x=11.2 \%$; b) $x=23.6 \%$; c) $x=$ $39.1 \%$ increases. As a result of the reaction evolution, the volume of said second phase increases gradually and two individual phases disperse semi-continuously (Figure $4 \mathrm{~b}$ ). At the point that the volume of PS phase becomes more dominant than of the rubber phase, phase inversion occurs. The continuous phase is now the PS phase dissolved in styrene/ethylbenzene and the dispersed phase is composed of the grafted or non-grafted rubber particles dissolved in styrene/ethylbenzene (Figure 4c). A similar behavior can be observed in systems containing dissolved polymers other than rubber [28-30].

\subsection{Stable polymerization behavior}

Figure 5 displays the variation progress of grafting behavior under different TEMPO/DP275B ratio. When no TEMPO is added, the GD of 9004 rubber increases quickly in the first 100 min interval, and afterwards tends to be relatively slow, owing to the high viscosity of polymerization system and the scarce diffusion of reactive species. Otherwise, with the increasing TEMPO dosage, GD becomes more and more linearly related to the reaction time during the grafting progress. And the relevant increasing rate also lowers gradually as $R$ increases from 0.33 to 1.17 due to an aforesaid depressed polymerization conversion and grafting rate. Those all results show that under a moderate dosage of TEMPO injected a relative stable polymerization behavior can be obtained.

As an auxiliary method, SEC analysis of the polymers was also carried out in order to elucidate the controlled polymerization progress. Figure 6 shows the comparative size exclusion chromatograms of $\mathrm{PS}_{\mathrm{f}}$ separated from the resultant composite while there is no TEMPO added and the $R$ value is 0.33 ,

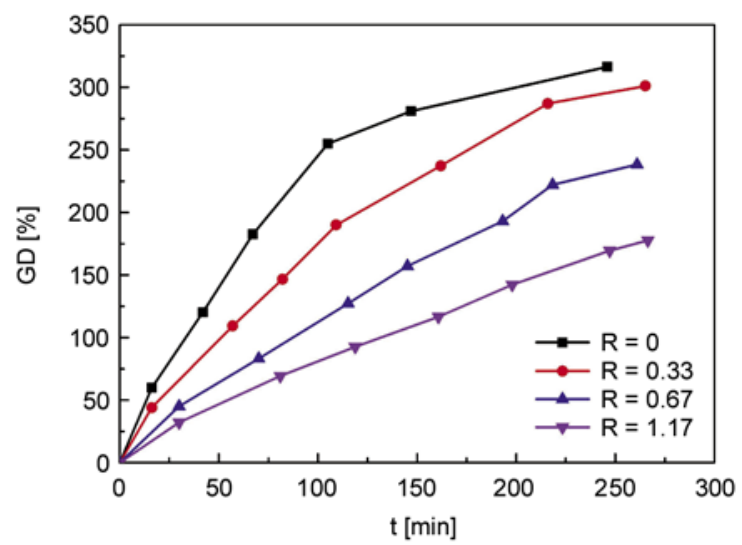

Figure 5. GD versus time under different $R$ values 

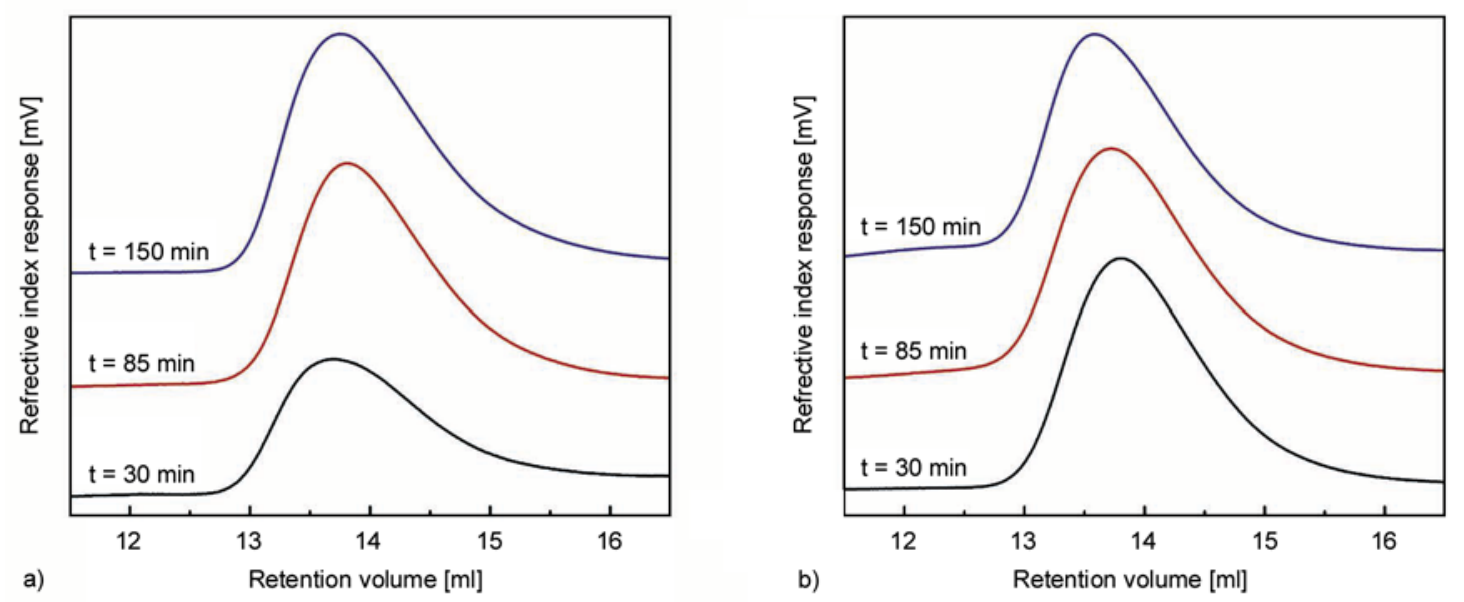

Figure 6. SEC curves of $\mathrm{PS}_{\mathrm{f}}$ at different time when no TEMPO added (a) and $R$ value is 0.33 (b)

Table 3. Molecular weight parameters of $\mathrm{PS}_{\mathrm{f}}$ under different $R$ values

\begin{tabular}{|c|c|c|c|c|}
\hline \multirow{2}{*}{$\begin{array}{c}\mathbf{1} \\
\text { [min] }\end{array}$} & \multicolumn{2}{|c|}{$\mathbf{R}=\mathbf{0}$} & \multicolumn{2}{c|}{$\mathbf{R}=\mathbf{0 . 3 3}$} \\
\cline { 2 - 5 } & $\mathbf{M}_{\mathbf{n}} \cdot \mathbf{1 0}^{-4}$ & Polydispersity & $\mathbf{M}_{\mathbf{n}} \cdot \mathbf{1 0}^{-4}$ & Polydispersity \\
\hline 30 & 10.8 & 4.558 & 6.7 & 2.189 \\
\hline 85 & 14.4 & 2.306 & 8.4 & 1.641 \\
\hline 150 & 12.8 & 2.010 & 9.1 & 1.314 \\
\hline
\end{tabular}

respectively. The relevant SEC results are listed in Table 3. Obviously, in the first case, once the polymerization occurs, PS macromolecules with higher molecular weight are formed besides those with lower molecular weight. This leads to a wider polydispersity value ( $>4.0)$. And the average molecular weight shows no significant variance and the polydispersity becomes narrower and decreases to 2.010. This can be attributed to the equilibrium of combination and disproportionation termination in typical free radical polymerization.

As for the second case, it maintains a relative narrower polydispersity value $(<2.2)$ all the time; more-

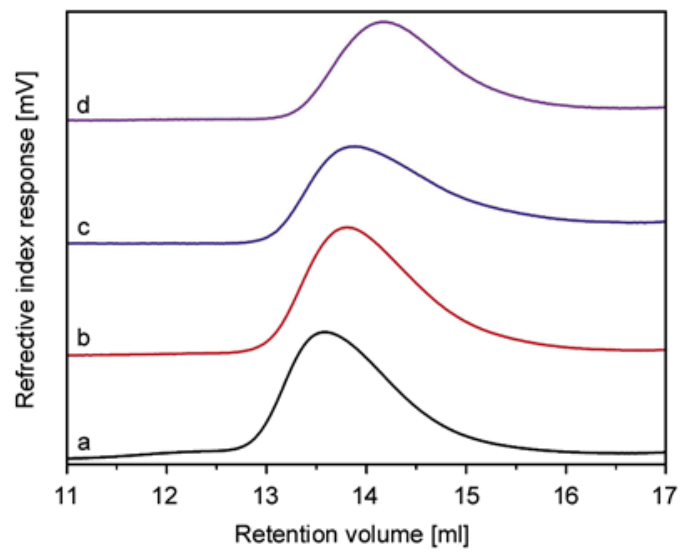

Figure 7. SEC curves of $\mathrm{PS}_{\mathrm{f}}$ under different $R$ values $(t=$ $30 \mathrm{~min})$ : a) $R=0$; b) $R=0.33$; c) $R=0.67$; d) $R=$ 1.17 over, the maximum peak of the retention curve gradually shifts toward left, that is, higher molecular weight region, which indicates an increased average molecular weight of $\mathrm{PS}_{\mathrm{f}}$ and a controlled growth of the end-functional chains. On the other hand, at the same reaction time $\left(30 \mathrm{~min}\right.$ ), the $\mathrm{PS}_{\mathrm{f}}$ phase presents a decreased molecular weight and a narrower polydispersity with the increase of TEMPO/DP275B ratio as shown in Figure 7. This also corroborates the foregoing conclusion of the controlled growth of chains and the stable polymerization behavior.

\subsection{Morphological and mechanical properties}

The structural and mechanical properties of the composites prepared with different TEMPO dosages are listed in Table 4. As shown, the yield stress and fracture stress have no great variance. However, the notched Izod impact strength and the elongation at break are quite different from each other; both show a significant downtrend with increasing the TEMPO/ DP275B ratio. Therefore, $R$ value has a strong influence on the impact property and fracture elongation by directly affecting the grafting level of elastomeric toughener. As one of the key factors, the interfacial performance has an important effect on the toughening modification. A moderate grafting level is beneficial to the distribution of rubber particles and the binding force between the two phases. On the other hand, the aforesaid great differences in toughness, to a large extent, are also attributable to the distinct morphological structures of as-prepared products. Figure 8 gives the TEM images of various PS composites obtained by changing $R$ value. As illustrated from Figure 8a, the composite without 
Table 4. Effect of $\mathrm{R}$ values on the molecular structures and mechanical properties of composites

\begin{tabular}{|c|c|c|c|c|c|c|c|c|}
\hline \multirow[b]{2}{*}{$\mathbf{R}$} & \multicolumn{2}{|c|}{ Rubber phase } & \multicolumn{2}{|c|}{ PS $_{\mathrm{f}}$ phase } & \multirow{2}{*}{$\begin{array}{c}\text { Notched Izod } \\
\text { impact strength } \\
{[\mathrm{J} / \mathrm{m}]}\end{array}$} & \multirow{2}{*}{$\begin{array}{c}\text { Yield stress } \\
\text { [MPa] }\end{array}$} & \multirow{2}{*}{$\begin{array}{c}\text { Fracture } \\
\text { stress } \\
{[\mathrm{MPa}]}\end{array}$} & \multirow{2}{*}{$\begin{array}{c}\text { Elongation } \\
\text { at break } \\
{[\%]}\end{array}$} \\
\hline & $\begin{array}{l}\text { GD } \\
{[\%]}\end{array}$ & $\begin{array}{c}\text { RPVF } \\
{[\%]}\end{array}$ & $M_{n} \cdot 10^{-4}$ & Polydispersity & & & & \\
\hline 0.00 & 345.5 & 35.4 & 14.6 & 1.565 & 28.4 & 32.8 & 29.9 & 37.4 \\
\hline 0.33 & 309.0 & 39.0 & 11.3 & 1.294 & 20.8 & 33.5 & 26.9 & 20.7 \\
\hline 0.67 & 261.6 & 41.8 & 11.0 & 1.288 & 16.2 & 33.6 & 24.9 & 36.4 \\
\hline 1.17 & 209.7 & 48.9 & 10.7 & 1.285 & 15.0 & 36.2 & 31.6 & 13.6 \\
\hline
\end{tabular}

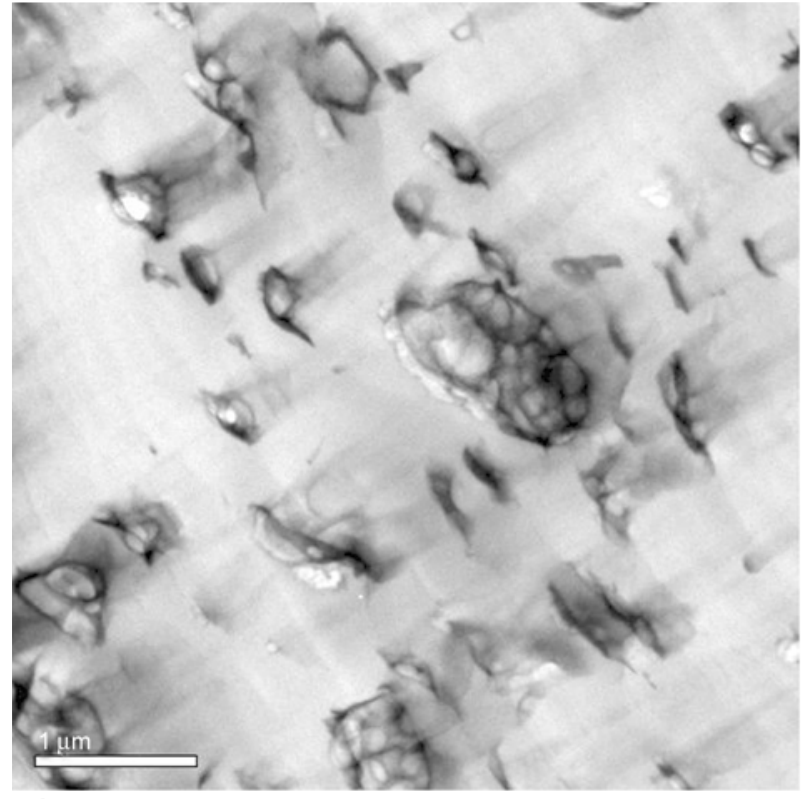

a)

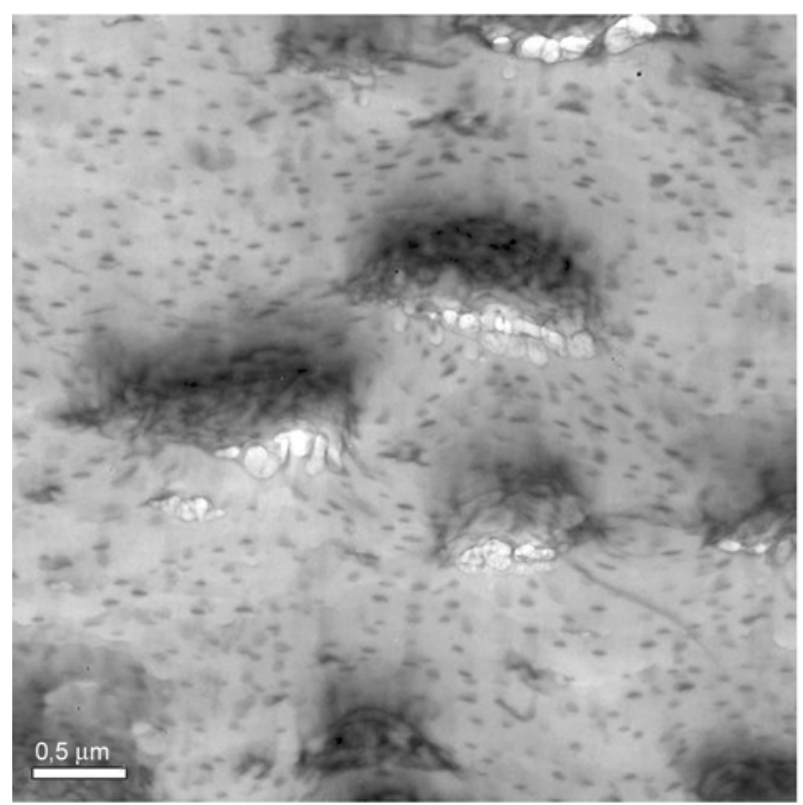

c)

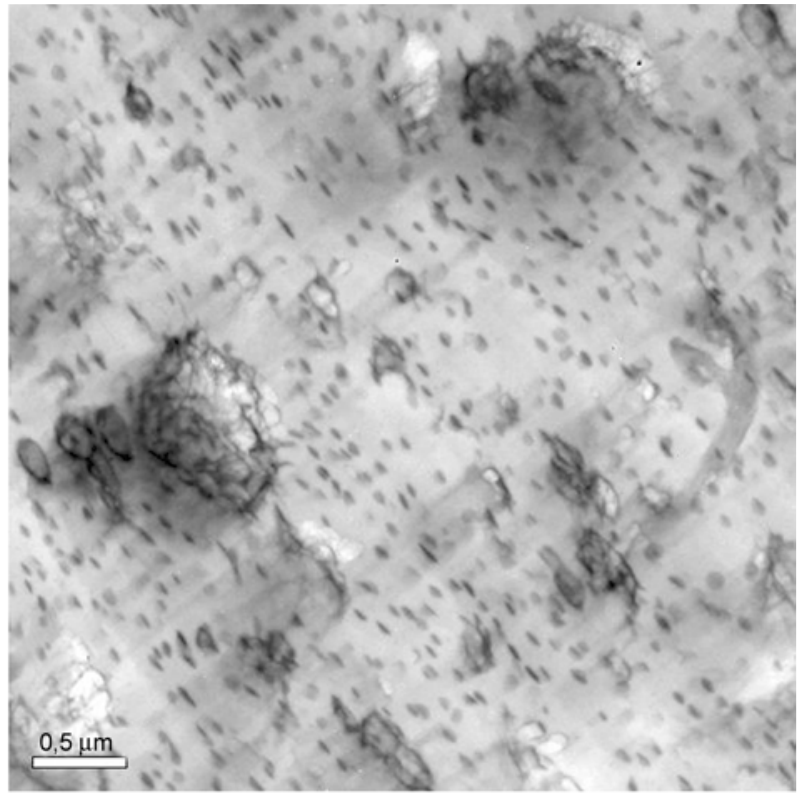

b)

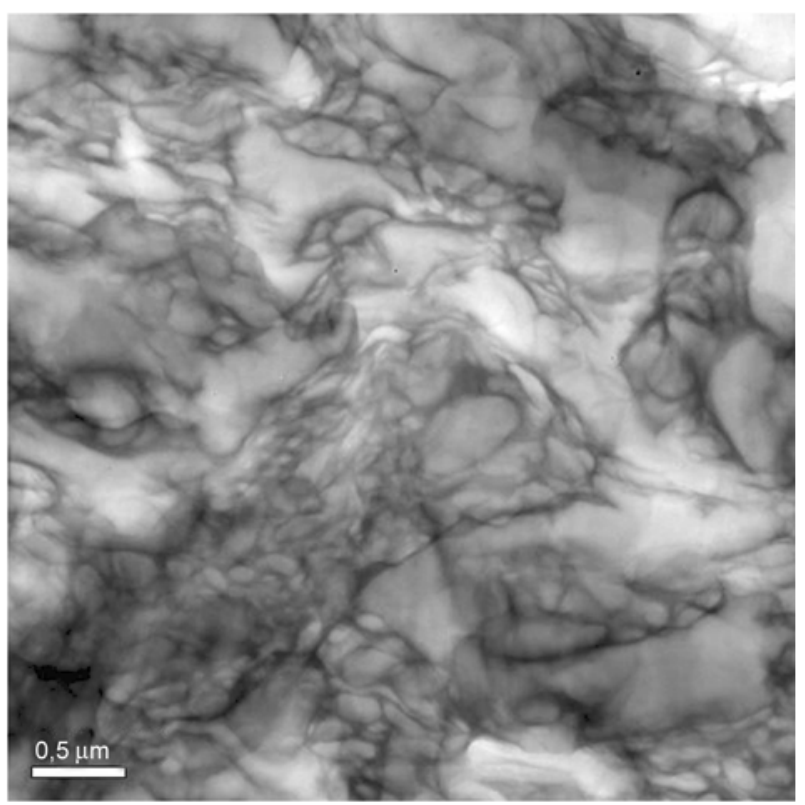

d)

Figure 8. TEM images of composites under different $R$ values: a) $R=0$; b) $R=0.33$; c) $R=0.67$; d) $R=1.17$

TEMPO possesses typical 'sea-island' structure with a wide distribution. A great many smaller particles $(\sim 300 \mathrm{~nm})$ and a few larger ones $(>1.0 \mu \mathrm{m})$ coexist. A large number of PS occlusions can be observed inside the larger particles while those smaller particles have almost no inclusions. The relatively clear interface and the hypodispersion of rubber phase may be due to the higher viscosity of polymeriza- 
tion system and the random distribution of grafting chains on the rubber particle surface.

In the case of $R$ value of 0.33 (Figure $8 \mathrm{~b}$ ), those smaller and larger particles in the composite similar to the former without TEMPO still exist. Besides, there appear homogeneously a mass of nanometergrade granules without inner grafting, the size of which is lower than $100 \mathrm{~nm}$. When $R$ value is increased to 0.67 , the number of larger particles increases and their size also tends to be uniform and is decreased to approximately $1.0 \mu \mathrm{m}$, which are attributable to the mediation action of TEMPO. Just because of those uniform larger particles having excellent stretching and yielding abilities under tensile, they endow the composite material with a higher elongation at break. However, the material shows poor anti-impact property while suffering an external impact force in that the existing micro-fine granules can not effectively terminate the development of crazes or restrain the propagation of cracks. Further increasing the TEMPO amount, the polymerization and chain extension occur very slowly. The relative lower grafting degree (209.7\%) is not enough to disperse the rubber phase, indicating a poor two-phase interface. And the amount of asproduced PS phase is not up to that of rubber phase in a certain reaction interval, either. As a result, as shown in Figure 8d, the semi-continuous state or interpenetrating network of two-phase is formed [28], which is further unfavorable to impact resistance property.

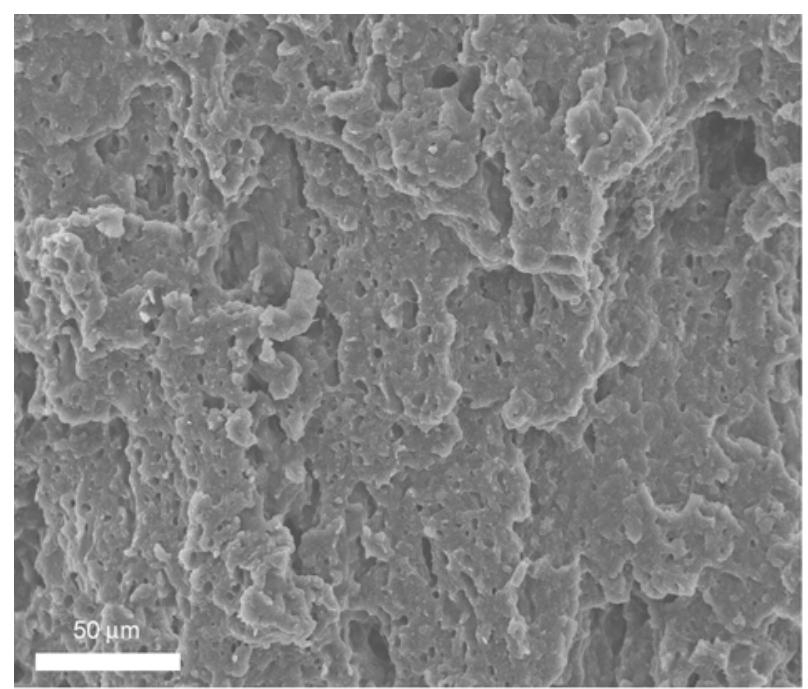

a)

\subsection{Fractography}

In order to deeply clarify the fracture mode and mechanism, the fracture surface morphologies of BR9004 rubber toughened PS composites with varying TEMPO/DP275B ratio after impact tests were observed by a scanning electron microscope. The corresponding images are shown in Figures 9-10, respectively. As can be seen from Figure 9a, the sample without TEMPO added totally shows a rather rough fracture surface and a certain degree of stresswhitening, suggesting that the plasticization and yielding phenomenon occur. Further amplifying the region, quite a few naked rubber particles and micron-grade cavities can be observed in the fractured surface. This means that the stress concentration releases effectively after the matrix stripping and the stress yielding. In a word, the dominating fracture mechanism in this case is the characteristic plasticization and yielding in the shear stress field. In contrast, there are three distinct morphological domains on the fractured surface with $R$ value of 0.33 as shown in Figure 10a. They are (i) mirror zone, (ii) rib-structure zone and (iii) rapid crack propagation zone, respectively. In the mirror zone (a range from notch to $500 \mu \mathrm{m}$ ), the fracture surface seems to be relatively flat and smooth, accompanied by only a few peeling patterns caused by the initiation and expansion of single or several crazes. While the crack propagates into the rib-structure zone, the rough band and the smooth band alternately appear (Figure 10b). The former are mainly

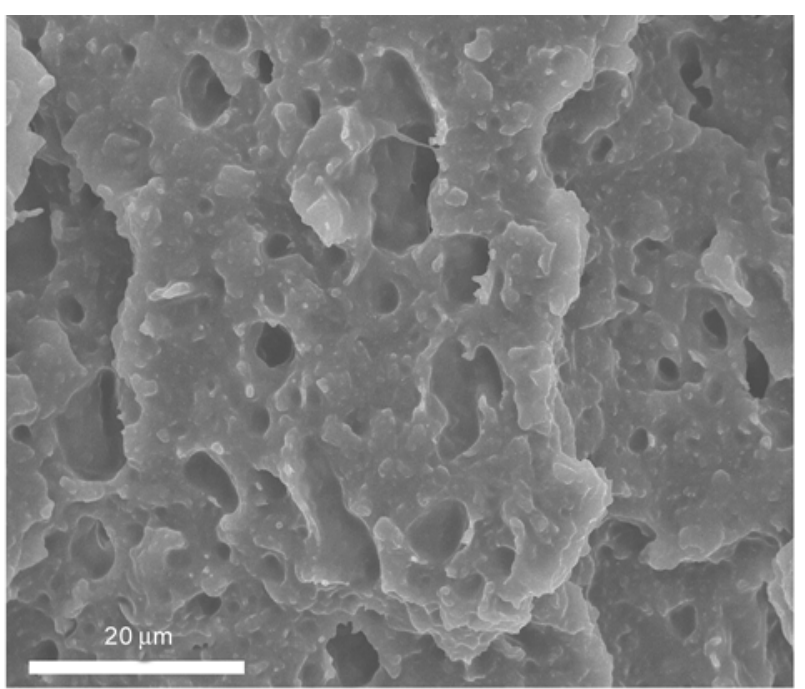

b)

Figure 9. SEM images of fracture surface of composite without TEMPO added 


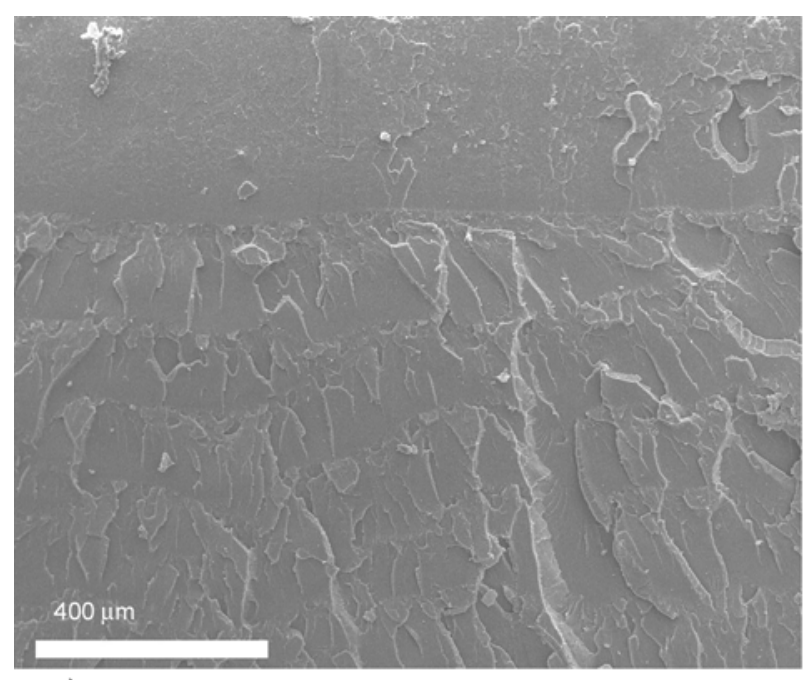

a)

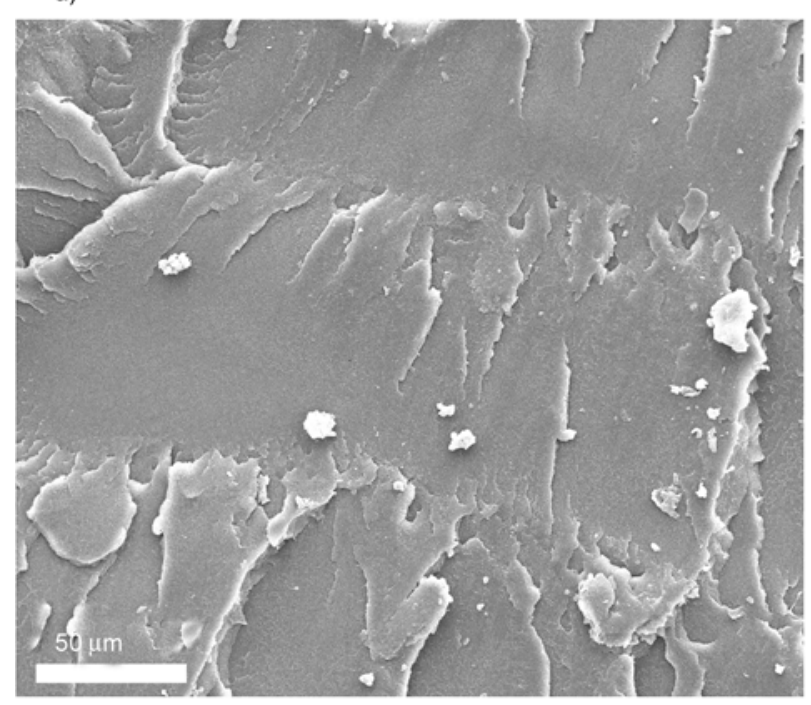

c)

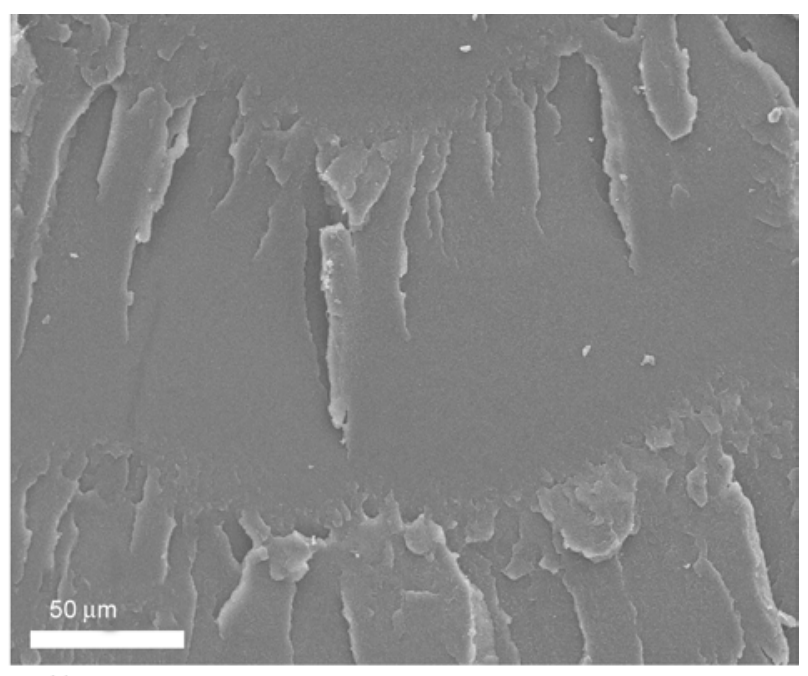

b)

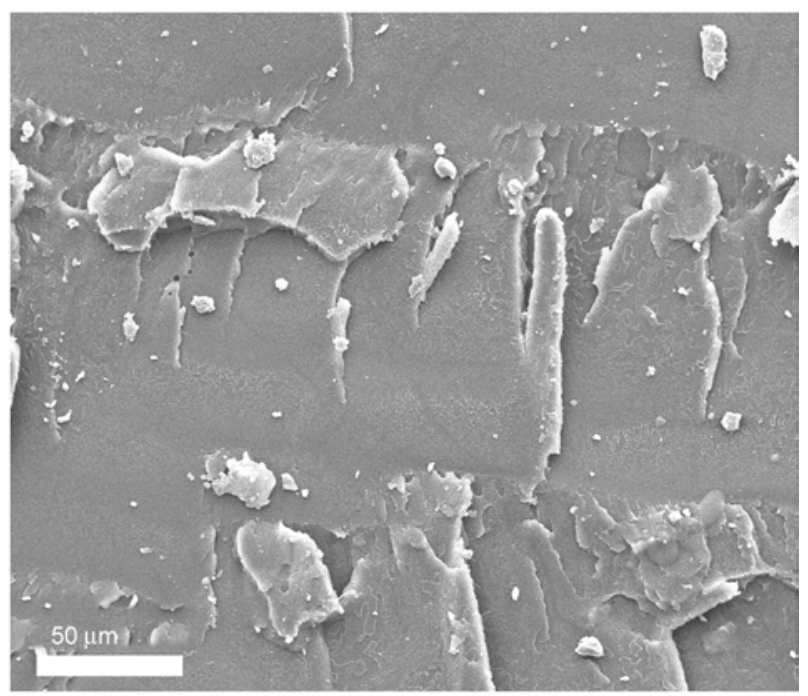

d)

Figure 10. SEM images of fracture surface of composites with various $R$ values: a) $R=0.33$; b) $R=0.33$; c) $R=0.67$; d) $R=1.17$

the dense cracks extending along the impact direction. Besides, stress-whiting is dramatic at the edge of those cracks, meaning a fatally tearing progress in the material. As for the latter, there exist almost no characteristics except a single crack from the rough band terminated here. Its appearance is the logical result of the external impact energy aggregating first and then releasing in the crack tip. In addition, with the cracks propagating, the spacing between rib-structures becomes narrower and narrower while the rough band gets wider and wider, demonstrating that the matrix material can not avoid unstable rupturing.

When $R$ value is increased to 0.67 and 1.17 , respectively, the composite materials basically present similar fracture surface morphology (Figure 10c-d). The substantive diversities lie in the peeling degree of craze patterns in the mirror zone, the band width and crack size in the rib-structure zone, and the propagating speed of cracks in the rapid crack propagation zone, etc. As seen, the more TEMPO is used, the more brittle the material becomes. Generally speaking, semi-ductile fracture occurs for the material with no or less TEMPO accompanied by pronounced cavitation and shear yielding, while for the material under the mediation of more TEMPO, alternate rough band and smooth band successively followed by fast developed cracks are obviously exhibited in the mode of quasi-brittle failure.

\section{Conclusions}

A well-controlled grafting polymerization of styrene onto the high-cis-1,4-PB rubber initiated by DP275B under the mediation of TEMPO. The grafting 
progress, grafting parameters of rubber and molecular weight of $\mathrm{PS}_{\mathrm{f}}$ while adding different TEMPO amount were determined, which showed that not only the grafting kinetics of styrene but the molecular weight of PS (free and grafted) can be well controlled besides a narrower polydispersity. The structure, mechanical properties and fracture mechanism of the composites were also evaluated. By adjusting the TEMPO/DP275B ratio to a certain degree, not only the finer rubber particles but the larger ones tended to be more homogeneous. Consequently, the material displayed relatively outstanding comprehensive mechanical properties. The relevant fracture mechanism was mainly cavitation and shear yielding. However, too much TEMPO applied was disadvantageous to the grafting and fine dispersion of rubber phase. Furthermore, the material exhibited poor physical properties and fractured in a quasibrittle mode. Totally, three distinct fracture zones on its fractured surface suggested a fast propagating progress of crack and an unstable failure of material.

\section{Acknowledgements}

This work was financially supported by the National High Technology Research and Development Program of China (No. 2007AA03Z532) and the National Natural Science Foundation of China (No. 20774015). The authors wish to thank Senior Engineer Chaoxian Wang for instrumented impact and tensile testing and Senior Engineer Ying Liu for electron microscopy investigations.

\section{References}

[1] Sirqueira A. S., Soares B. G.: Mercapto-modified copolymers in elastomer blends. IV. The compatibilization of natural rubber/EPDM blends. Journal of Applied Polymer Science, 83, 2892-2900 (2002). DOI: $10.1002 /$ app.10283

[2] Lee D-Y., Subramaniam N., Fellows C. M., Gilbert R. G.: Structure-property relationships in modified natural rubber latexes grafted with methyl methacrylate and vinyl neo-decanoate. Journal of Polymer Science Part A: Polymer Chemistry, 40, 809-822 (2002). DOI: $10.1002 /$ pola.10165

[3] Whan J., Paul D. R. C.: Glass fiber-reinforced polyamide composites toughened with ABS and EPR- $g$ MA. Journal of Applied Polymer Science, 80, 484-497 (2001).

DOI: $10.1002 / 1097-4628(20010418) 80: 3<484:: A I D-$ APP1122>3.0.CO;2-5
[4] Taylor N. W., Bagley E. B.: Tailoring closely packed gel-particle systems for use as thickening agents. Journal of Applied Polymer Science, 21, 113-122 (1977). DOI: $10.1002 /$ app.1977.070210110

[5] Arnold M., Knorr J., Köller F., Bornemann S.: Modified polypropenes via metallocene catalysis. Journal of Macromolecular Science Part A: Pure and Applied Chemistry, 36, 1655-1681 (1999).

DOI: $10.1081 / \mathrm{MA}-100101619$

[6] Stehling U. M., Malmstrom E. E., Waymouth R. W., Hawker C. J.: Synthesis of poly(olefin) graft copolymers by a combination of metallocene and 'living' free radical polymerization techniques. Macromolecules, 31, 4396-4398 (1998).

DOI: $10.1021 / \mathrm{ma9} 80141+$

[7] Davis K. A., Matyjaszewski K.: Statistical, gradient, block and graft copolymers by controlled/living radical polymerizations. Advances in Polymer Science, 159, 107-152 (2002).

DOI: $10.1007 / 3-540-45806-9$

[8] Hawker C. J., Bosman A. W., Harth E.: New polymer synthesis by nitroxide mediated living radical polymerizations. Chemical Reviews, 101, 3661-3688 (2001). DOI: $10.1021 / \mathrm{cr} 990119 \mathrm{u}$

[9] Bani F., Abbasian M., Taromi F. A., Entezami A. A.: Polystyrene grafted to ABS backbone by living radical polymerization with TEMPO. Iranian Polymer Journal, 13, 513-520 (2004).

[10] Yamanaka A., Izumi Y., Kitagawa T., Terada T., Sugihara H., Hirahata H., Ema K., Fujishiro H., Nishijima S.: The radiation effect on thermal conductivity of high strength ultra-high-molecular-weight polyethylene fiber by $\gamma$-rays. Journal of Applied Polymer Science, 101, 2619-2626 (2006).

DOI: $10.1002 /$ app. 24227

[11] Lu H. L., Chung T. C.: Synthesis of PP graft copolymers via anionic living graft-from reactions of polypropylene containing reactive p-methylstyrene units. Journal of Polymer Science Part A: Polymer Chemistry, 37, 4176-4183 (1999).

DOI: 10.1002/(SICI)1099-0518(19991115)37:22<4176 $\because$ AID-POLA17>3.0.CO;2-O

[12] Kennedy J. P., Vidal A.: Block and graft copolymers by selective cationic initiation. III. Synthesis and characterization of bigraft copolymers. Journal of Polymer Science, Polymer Chemistry Edition, 13, 1765-1781 (1975).

DOI: $10.1002 /$ pol.1975.170130803

[13] Moad G., Solomon D. H.: The chemistry of radical polymerization. Elsevier, Oxford (2006).

[14] Miwa Y., Yamamoto K., Sakaguchi M., Shimada S.: Well-defined polystyrene grafted to polypropylene backbone by 'living' radical polymerization with TEMPO. Macromolecules, 34, 2089-2094 (2001). DOI: $10.1021 / \mathrm{ma} 001449 \mathrm{f}$ 
[15] Wayland B. B., Poszmik G., Mukerjee S. L., Fryd M.: Living radical polymerization of acrylates by organocobalt porphyrin complexes. Journal of the American Chemical Society, 116, 7943-7944 (1994).

DOI: $10.1021 / \mathrm{ja} 00096 \mathrm{a} 080$

[16] Benoit D., Chaplinski V., Braslau R., Hawker C. J.: Development of a universal alkoxyamine for 'living' free radical polymerizations. Journal of the American Chemical Society, 121, 3904-3920 (1999). DOI: $10.1021 /$ ja984013c

[17] Solomon D. H., Rizzardo E., Cacioli P.: Polymerization process and polymers produced thereby. U.S. Patent 4581429, USA (1986).

[18] Roth M., Pfaendner R., Nesvadba P.: Grafting of ethylenically unsaturated monomers onto polymers. U.S. Patent 6521710, USA (2003).

[19] Roth M., Pfaendner R.: Grafting of ethylenically unsaturated monomers onto polymers. U.S. Patent, 6525151 (2003).

[20] Abbasian M., Namazi H., Entezami A. A.: 'Living' radical graft polymerization of styrene to styrene butadiene rubber (SBR) with 2,2,6,6-tetramethyl-1-piperidinyloxy (TEMPO). Polymers for Advanced Technologies, 15, 606-611 (2004).

DOI: $10.1002 /$ pat.515

[21] Miwa Y., Yamamoto K., Sakaguchi M., Shimada S.: 'Living' radical graft polymerization of styrene to polypropylene with 2,2,6,6-tetramethylpiperidinyl-1-oxy. Macromolecules, 32, 8234-8236 (1999).

DOI: $10.1021 / \mathrm{ma} 990998 \mathrm{~m}$

[22] Miwa Y., Yamamoto K., Sakaguchi M., Shimada S.: Well-defined polystyrene grafted to polypropylene backbone by 'living' radical polymerization with TEMPO. Macromolecules, 34, 2089-2094 (2001). DOI: $10.1021 / \mathrm{ma} 001449 \mathrm{f}$

[23] Braunecker W. A., Matyjaszewski K.: Controlled/living radical polymerization: Features, developments, and perspectives. Progress in Polymer Science, 32, 93146 (2007).

DOI: $10.1016 /$ j.progpolymsci.2006.11.002
[24] Gromadzki D., Makuška R., Netopilik M., Holler P., Lokaj J., Janata M., Štěpánek P.: Comb copolymers of polystyrene-poly(tert-butyl (meth)acrylate) prepared by combination of nitroxide mediated polymerization and photoinduced iniferter technique. European Polymer Journal, 44, 59-71 (2008). DOI: $10.1016 /$ j.eurpolymj.2007.10.024

[25] Howell B., Zhu Y., Zeng W., Lyons J., Meunier D., Demirors M., Priddy D.: Application of living radical polymerization to enhance grafting of PS onto PBD. Polymeric Preprints, 40, 73-74 (1999).

[26] Bonilla-Cruz J., Saldívar-Guerra E., Torres-Lubián J. R., Guerrero-Santos R., López-Carpy B., Luna-Bárcenas G.: Controlled grafting-from of polystyrene on polybutadiene: Mechanism and spectroscopic evidence of the functionalization of polybutadiene with 4oxo-TEMPO. Macromolecular Chemistry and Physics, 209, 2268-2283 (2008).

DOI: $10.1002 / \mathrm{macp} .200800367$

[27] Scheirs J., Priddy D. B.: Modern styrenic polymers: Polystyrenes and styrenic copolymers. Wiley, New York (2003).

[28] Freeguard G. F., Karmarkar M.: The production of rubber-modified polystyrene. I. Rheological behavior of the polymerizing system. Journal of Applied Polymer Science, 15, 1649-1655 (1971). DOI: 10.1002/app.1971.070150708

[29] Molau G. E., Keskkula H.: Heterogeneous polymer systems. IV. Mechanism of rubber particle formation in rubber-modified vinyl polymers. Journal of Polymer Science Part A-1: Polymer Chemistry, 4, 15951607 (1966).

DOI: $10.1002 /$ pol.1966.150040622

[30] Molau G. E.: Heterogeneous polymer systems. I. Polymeric oil-in-oil emulsions. Journal of Polymer Science Part A: General Papers, 3, 1267-1278 (1965). DOI: $10.1002 /$ pol.1965.100030402 